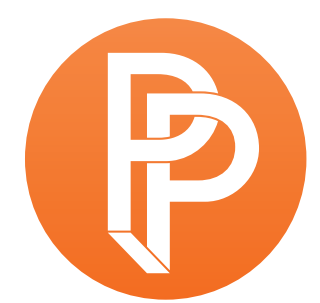

PERFORMANCE

PHILOSOPHY

\title{
AN-AESTHETIC: PERFORMED PHILOSOPHIES OF SENSATION, CONFUSION, AND INTOXICATION
}

\author{
PAUL GEARY UNIVERSITY OF EAST ANGLIA
}

\begin{abstract}
Words fill our flesh and anæsthetize it. It has even been said, and written, that the word was made flesh. Nothing makes one more insensitive than words.
\end{abstract}

Anæsthetic robs us of æsthetics. [...] Æsthetics cures us of anæsthesia. [...] Fine wine works on the tongue, awakening it from its narcotic slumber.

Michel Serres $(2016,58,156)$

\section{Introduction}

In Michel Serres' The Five Senses: A Philosophy of Mingled Bodies ([1985] 2016), he establishes a relationship between aesthetics and anaesthesia. Two terms that tend to circulate in different fields-the arts and medicine respectively-they share a root in aisthesis, meaning sensation or perception. Anaesthesia is the negation or absence of aisthesis, the removal, withdrawal or numbing of sensation. And for Serres, the language of discourse inculcates anaesthesia of the mouth; the removal of the sensation that is found in what he calls a second mouth, the mouth of tasting. Anaesthesia steals away from aesthetics as both art and sensation; aesthetics (re)introduces sensation and awakens us from the 'narcotic slumber' of discourse. 
In this article, I explore Serres' writing on the senses, particularly in relation to his conception of two mouths: the first, the anaesthetising mouth of discourse, the second, the sensate mouth of aesthetics and experience. Serres uses these two mouths as indicative of two modes of knowledge: dissecting analysis and sapience or embodiment, respectively. Both Performance Philosophy and Practice-as-Research have troubled the separation of these two arenas of knowledge and, in The Five Senses, Serres does gesture towards their inseparability in writing about confusion and confluence; their pouring together in knowledge and experience. Here, I use the two mouths and two orders of knowledge to consider the 'thinking', knowledge or understanding that can be at work in intoxication and in sensory experience.

Intoxication is understood here in relation to Serres' two mouths in two modes: the first, anaesthetising intoxication, whereby one unthinkingly loses oneself into political and cultural codes - intoxication as a loss of critical faculties; the other, intoxication as a process of 'making strange' and opening a conceptual and felt space for considering and reflecting upon one's own body and experience. Increasingly, different kinds of experience are coopted as 'live(d) experience' within a culture of commodification. Given that this is increasingly the cultural status quo, where experience itself becomes a commodity, in intoxication we could merely give ourselves over to this cultural logic and, in an ever-growing quest for novelty, seek out and pay for experience for the sake of having experienced. But there's also potential for that second kind of intoxication, where the quotidian is made strange, defamiliarised, and our own bodies and experiences can become a site of resistance, becoming aware of themselves. Using Serres, this article explores how this kind of knowledge-work of defamiliarising intoxication can engender a self-reflective process of understanding one's own construction as an experiencing, political subject.

The article begins with a theoretical outline of Serres' two mouths, intoxication and the politics of sensory experience. This is then followed with a more personal reflection on the experience of a dining-performance event: After Dark (2016). ${ }^{1}$ After Dark was a pop-up restaurant performance event designed by Kaye Winwood in collaboration with chef Chris Hughes and designer Nuala Clooney. The event offered a curated tasting menu of nine courses, some with accompanying alcoholic drinks and explored connections between food, sensuality and sexuality, with performers guiding the audience-diners through the meal. Beginning with a series of small tantalising tasters, moving through oyster, tomato and lamb dishes and ending with chocolate and tobacco desserts, each of the courses attempted to draw out ideas around the body, sex and encounters with the body of another, drawing attention to, heightening and problematising acts of touching and eating. And here I consider the particular experiential reflections that emerged, for me, in that event and how, in its intoxications, it made strange aspects of the everyday experience of eating and my own body. 
In The Five Senses, Michel Serres calls for us to

\begin{abstract}
awaken the palate from anæsthetizing talk through the use of a second talent. Which discovers an æsthetics of sense in the work of a different, artistic æsthetic. [...] One mouth chases the other, the mouth of discourse excludes the mouth of taste, expels it from discourse. $(2016,154)$
\end{abstract}

For Serres, a particular kind of language, that of discourse, which analyses and dissects, anaesthetises the mouth, forcing that other mouth, the tasting and sensate mouth, to slumber. For Serres, there is a conceptual tension between the two mouths, where one offers knowledge of the order of discourse, analysis and dissection and the other the knowledge of embodiment, the senses and experience. Serres seemingly separates the two constituent parts of Performance Philosophy: the embodied or aesthetic and knowledge or understanding. He continues

\begin{abstract}
Many philosophies refer to sight; few to hearing; fewer still place their trust in the tactile, or olfactory. Abstraction divides up the sentient body, eliminates taste, smell and touch, retains only sight and hearing [...]. To abstract means to tear the body to pieces rather than merely to leave it behind: analysis. (26)
\end{abstract}

Serres proposes this separation as a means of legitimising the knowledges of sensate embodiment and critiquing analysis in its leaving out of the body. He writes of the Occidental philosophical and cultural tradition, which privileges the seemingly 'higher' and distanced senses of sight and sound; those senses that seemingly offer a more 'objective' perspective and remove the personal, the sensory and the messy from knowledge construction. ${ }^{2}$ He connects this to a process of abstraction and dissection; the tearing apart of the body into its separate sensory streams and, beyond that, the dissection that allows for the study of an abstracted stream of experience of the world.

Serres offers this separation of modes of knowledge to consider the knowledge, understanding or revelation(s) that emerge from embodied and sensory experience, which he calls 'sapience'. He writes that

\footnotetext{
homo sapiens refers to those who react to sapidity, appreciate it and seek it out, those for whom the sense of taste matters [...] before referring to judgement, intelligence or wisdom. [...] Sensation, it used to be said, inaugurates intelligence. Here, more locally, taste institutes sapience. $(2016,155)$
}

'Sapidity' comes from the Latin root sapere, meaning 'to taste', and 'sapience' from sapientia, meaning 'good taste', 'good sense', 'wisdom' or 'intelligence'. Just as the English colloquialism 'I see' means both to have vision and to understand, so too does sapience have this double meaning of taste and wisdom. 'I see' is of the order of knowledge of discourse, the knowledge derived of distanced rationality and connected to that 'higher' sense of sight. Sapience is knowledge of a different order, one grounded in the body, in the 'lower' sense of taste. 
However, these two mouths and their separate orders of knowledge are not so easily teased apart. Indeed, Serres does go on to propose a philosophy of 'confusion', which brings them together in the flow of thinking and experience. Far from the negation of understanding (the everyday usage of 'confusion'), Serres posits knowledge, confusion and confluence in terms of, 'a theory of knowledge, less solid than a solid, almost as fluid as a liquid, hard and soft: fabric.' (Serres 2016, 81) He writes that

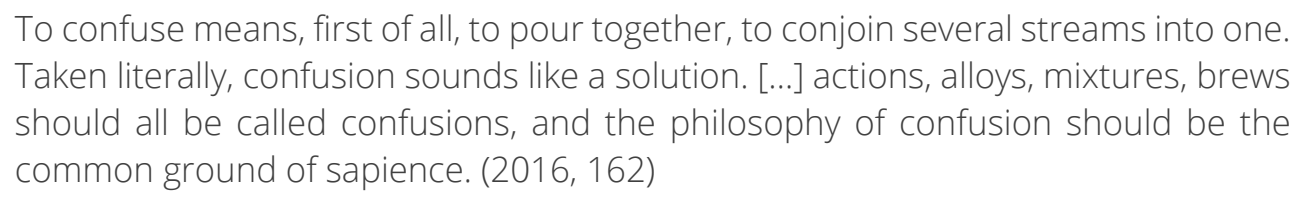

There is a tension between the two mouths, between discourse and sapience, for Serres, but he also deals with their flowing together: the knowledges of intersections, where bodies, experience, ideas, discourses, histories and cultures flow together; an understanding of the performed nature of knowledge that is grounded in the live(d) body who 'knows' and the streams mixing and pouring and flowing together, where any one of these streams of understanding taken separately cannot give an account of the world and experience as it is. It is the knowledge not strictly of discourse (discursus, running to and fro) but of concourse (concursus, running together). Between the two mouths, Serres opens a conceptual space for their interaction and intersection.

Given the interrelation of the aesthetic and anaesthetic, their emergence from and differential relations with one another, they should not be considered separate in terms of the knowledgework of performance. We might instead talk of the 'an-aesthetic', with the dash fulfilling a grammatical function that cleaves apart the aesthetic from the anaesthetic while nevertheless recognising their inseparability. And this an-aesthetic can be used as a means of thinking about intoxication in performance; both literal intoxication resulting from consumption, but also the figurative intoxicating effects of performance. In both cases, the body itself is revealed as caught in this confusion; in the pouring together of different kinds of knowledge and their mixing in the live(d) experience of an event; on, in and through the body.

Intoxication has the potential to draw attention to our own bodies; in it, the quotidian can be made strange and, in so doing, allow for qualities, forms and ideas to emerge as separate from one's own intuitive or spontaneous experience. In Frederic Jameson's writing on Brecht and 'estrangement', he argues that

\footnotetext{
To make something look strange, to make us look at it with new eyes, implies the antecedence of a general familiarity, of a habit which prevents us from really looking at things, a kind of perceptual numbness [..., a defence of innovation in terms of the freshness of experience and the recovery of perception. (1999, 50, my emphasis)
}

The process of making strange, in this formulation, is bound up with the senses; of recovering (or perhaps discovering) a new attentiveness to sensory experience. Out of the 'perceptual numbness', or anaesthetising qualities, of familiarity with the quotidian arises a defamiliarising process where 
the senses are experienced afresh, with an awareness of the qualities of that experience that might usually go unnoticed or unremarked, in the background as it were. Part of the historical relegation of taste, smell and touch to the realm of the 'lower' senses is that they are seen as somehow too entangled with personal preference; that we are reduced to judgements of liking and disliking, to judgements of personal pleasure, while the 'higher' senses of sight and sound offer a more complex and distanced range of reflective qualities. Intoxication, as a process of making strange in the body, can move us away from a quotidian experience of the body and from that sensory hierarchy; to adopt a perspective on our own experience that is distanced from personal preference, from seemingly intuitive tastes and to become aware of the process of embodiment. In other words, intoxication can produce a self-reflective knowledge, acknowledging one's own body and how it senses, revealing it as always already a process shifting between dissecting analysis and sensory awareness.

While intoxication has potential to defamiliarise, to make strange and to trouble everyday experiences of the senses, in an economy increasingly grounded in, and capitalising on, 'live experience', the momentary, transitory and sensual begins to lose its radical-political potential. Too easily the revelations and understandings of the live event can slip into the realm of commodity, of cultural capital. And while intoxication can make strange and furnish us with an experience that reflects on the body and the quotidian, it too can easily slip into a different mode whereby we lose ourselves into cultural scripts and codes. In writing on psychedelic drugs in Screened Out, Jean Baudrillard talks of the cultural anaesthesia that drugs can offer. He writes that

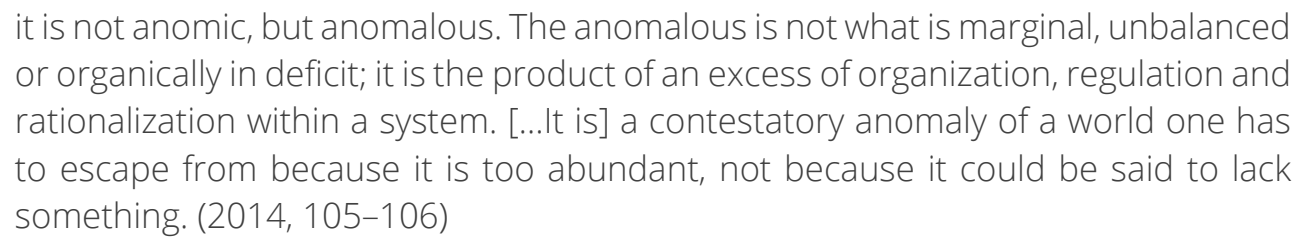

It is the abundance of the anaesthetising and austere institutions, those institutions that Serres conceives as producing the anaesthetising discourse from which the tasting mouth needs to be awakened, that drives the need to escape into heightened sensation. By this logic, intoxication can take another form: that of giving oneself over to the world of others, merging with the crowd and the cultural status quo. This experience of intoxication can offer a means of escape from an overdetermined world. Its pleasures and the understandings it brings are severely limited to the realm of the personal and individual as a means of defence against the organisational, regulatory and rationalised contemporary paradigm. And so the experience offered by intoxication may very well be in the realm of revelation and self-reflexive awareness, but equally could merely offer a self-indulgent escape that constructs a knowledge of the self as autonomous as a political operation to mask the commodification of the body and sensory experience.

To understand, or perhaps experience, intoxication as a making strange has the potential to counter the commodification of sensory experience. In intoxication our perceptual mode can be shifted from the everyday and the everyday itself can be made strange, altered. Serres writes that 'Consciousness belongs to those singular moments when the body is tangential to itself' $(2016,22)$. 
If we read consciousness in a way akin to Marxist 'class consciousness', a becoming-aware of one's own construction as an embodied subject within a particular social and political system, then becoming-conscious through intoxication is a process by which the body becomes tangential to itself, where it sits intimately alongside itself. Intoxication can intervene at the level of embodied and sensate experience, troubling the easy congruity of our schematised knowledge of the world, ourselves and our experiences. Intoxication can draw attention to our enculturation, which is always already at work at the level of experience; of what is sensible and where our attention is directed. It can intervene in experience itself, opening up space for an altered (self-reflexive) knowledge. Not wholly separate, nor a totalised experience of subjectivity, intoxication can shift us to look obliquely at ourselves. We can be made strange from ourselves and our experience, with our consciousness or sense of self slipping back and forth between experience and reflection, dwelling in that in-between.

\section{After Dark: An Experience of Confusion}

In the following section of the article, I turn to Winwood's After Dark, to consider how these ideas around intoxication, the senses and knowledge or reflection can be understood in practice; how, for me, they were made manifest in a live and experienced event. The work opened up a space for a kind of embodied self-reflection and, as such, the reflections themselves emerge from my own experience, as well as speaking to and of broader questions of the sensate and sensual body.

In The Five Senses, Serres discusses the relationship between the night and the senses. He writes

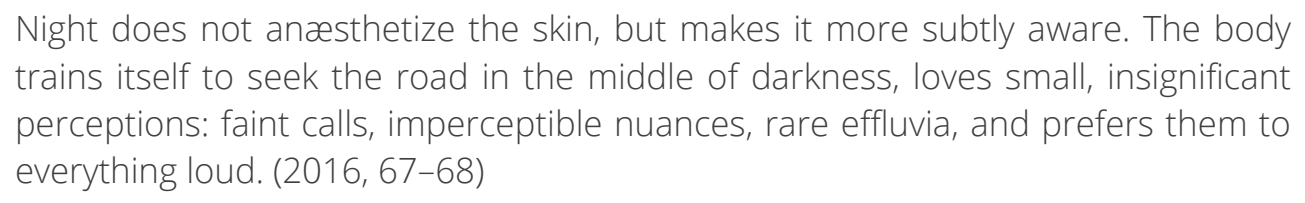

For Serres, that tension between aesthetics and anaesthesia arises once more. The dulling of some of the senses (light abating) leads to a heightening of attentiveness among the other senses; makes the body more aware to the subtle, the nuanced, the often overlooked. Winwood played with this in After Dark, utilising the change in light to shift the perceptual mode of the diners to be more attentive to their own embodied experience and, by extension, to the aesthetic and artistic operations of individual dishes and the overall event. The event took place at Two Cats restaurant in the Jewellery Quarter of Birmingham (UK) at dusk. In the first 30 minutes of the work, the light from outside, coming through the windows, changed and we were moved into dusk and then darkness outside, with dim lighting inside. The event utilised that transitional time of dusk, itself often associated with the emergence of nighttime activities. The senses themselves are revealed to be subject to shifts and changes, reflecting the broader context within which they are operating. This background to the event framed it; the environment through which the knowledges and revelations of the event would flow. 
The first course of the event was 'Honeypot', a gin, honey and thyme drink poured into the mouth of the diner by a performer. Served in a smaller space before moving in the main dining room, on plush chairs with dim lighting, the drink was served from small cups, the rim of which was shaped as lips. The performer gently placed her fingers under my chin, tilting my head back slightly to bring my lips upwards to meet the cold lips of the cup, from which was dribbled the drink into my mouth, with a little hitting the lips. This opening sensation was sweet, fragrant, alcoholic and intoxicating. The gentle touch of the performer was coupled with the feel of another's lips meeting my own. Serres writes that 'Taste is a kiss that our mouth gives itself through the intermediary of tasty foods. Suddenly it recognizes itself, becomes conscious of itself, exists for itself' $(2016,224)$. This drink did just that. I kissed the lips of another and in that kiss received something sweet and sticky; a bold flavour that coupled the harsh sting of gin with the soft sweetness of honey and the floral and slightly medicinal thyme. My experience was one of mixture and confusion and confluence; the different flavours pouring together. There was a kind of self-reflexivity to the experience, where each element (gin, honey, thyme, cold fingers, comfortable chair, head tilted back, stickiness on the lips...) was identifiable, but the identification of those individual parts was not enough to give an account of the experience. To know, to understand, to give an account of the experience in terms of its constituent parts, dissected, felt insufficient. The experience seemed to resist any totalising narrative of knowledge I attempted to assign to it.

One of the confusions of this drink was in its making strange of the experience of drinking and of kissing. Two activities that might usually require little to no thought, the experience of both was interrupted and changed, but not to the extent where it became an entirely different activity. I drank, but was not in control of how much or able to use my hands to guide where the drink was poured. I was kissed, but not by the lips of another person directly, but by the model of the lips of another, transformed into hard material that did not give or respond to the pressure of my own. Embodied memories of previous kisses and drinks were recalled precisely in the strangeness of this present experience to those of the past. It was not entirely new; it bore the traces of something familiar, something that goes without thinking. But nevertheless it was strange and so my attention was drawn to the very experience that is usually taken for granted. I was forced to experience my own body and its sensations in a different way and, in that, to recognise the feedback loop that allows me to control the act of drinking (my mouth is full so I pause, it is pouring too quickly so I tilt the cup away, the stinging sensation of alcohol causes me to gag momentarily so I stop and swallow); and to recognise the relationality of the kiss, which emerges as a meeting of my live lips with those of another, where here I was met with blank indifference, the lips of the other transformed into mere materiality, devoid of subjectivity. Perhaps more importantly, these things happened simultaneously, along with other sensory inputs that formed, both directly and indirectly, the horizon of the experience.

This was continued with the next course, but taken further, where caviar was served on a spoon modelled on the inside of another's mouth. The bowl of the spoon was moulded and shaped from the inside of the artists own mouth and when turned upside down in the mouth, my tongue could trace the roof of a mouth and the back of teeth that were not my own. The experience forced an engagement with my own individuality, my own sense of being an individual body, with its own 
traits and eccentricities. My tongue hit the roof of a mouth that was not my own; it was in the place where my own usually resides and there were similarities, yet it was not mine; I was teased with the tiniest experience of inhabiting the body of another. With both the lips on the cup and the mouth on the spoon, I imagined my own embodied nature, the lingering of subjectivity in the material, and was confronted with my future: the moment when I will become only lifeless material, when I will be entirely anaesthetised. This was not just illustrative of these ideas, but encouraged them to be recognised in experience itself; the body in its embodiment forming the basis of reflection and understanding. In these first courses, the event encouraged a particular attentiveness to one's own body. By doing this, the body itself is made strange; everyday acts (of drinking, of kissing, of feeling the roof of your mouth with your own tongue) were defamiliarised. My own sense of self, as a body, in a body, was called into question.

In terms of the wisdom and discernment of sapidity and sapience, our own tastes and personal preferences are alienated from themselves. Intoxication allows for a certain distance (by virtue of the tension between aesthetic sensation and anaesthetic numbing) in which we are caught, which allows us both to experience taste and to take a distanced perspective on it. The various sensory qualities of tasting (flavour, taste, temperature, texture, temporality) are split from a direct and immediate personal (dis)liking. Personal preferences are a result of a complex of past experiences, enculturation and associations, which intoxication allows us to take a step away from in order to appreciate these other aesthetic (sensate) qualities. And this is the first gesture towards an appreciation of eating, tasting and, more broadly, sensory experience as not just aesthetic but artistic; to consider its forms and qualities, its significations, its engagements with and reflections on culture, politics, history and ideas. In other words, as intoxication begins to anaesthetise that most personal and immediate sense of self, personal taste, it makes space for sensory experience to appear more clearly, though of course there is no neutral or pure sensory experience; it will always carry, to greater or lesser extents, the markers of the personal (taste, previous experience, understanding and preference).

The 'main course' of the After Dark meal was the eponymous title of the event: 'After Dark'. The dish was a black plate on which was served dark or black ingredients: charred lamb, aubergine, octopus, quinoa, trompettes de la mort and ash, served with a glass of Malbec. Coming after a number of dishes and experiences that had enlivened and awoken the senses, as well as a number of alcoholic drinks, this part of the meal was more sedate and less openly provocative. While the dish made use of bitter and dark flavours that can often be unpalatable, the various intoxications of the alcohol and the performance allowed for the dish to be experienced in terms of its sensory and conceptual qualities. The ash in particular, included in the dish, was transformed from unpalatable refuse (burnt remains) into a palatable and conceptual component of the work. Following the narrative established in the opening of the meal of the tension between sensuality and death, the food literally became ash in the mouth. But intoxication allowed for this to be experienced as aesthetic and artistic; not just disgustingly bitter, but an appeal to a particular part of my tasting sensory apparatus, allowing me to experience without immediately leaping to personal (dis)like. Emerging from the anaesthetising language that described this element as (unpalatable) ash, the second mouth was awoken in a differential relationship with the first and, with my immediate and 
spontaneous reactions dulled, the qualities of the ingredient-its bitterness, powderiness, its mixing with saliva to form a paste in the mouth, the addition of a darker quality in taste as well as vision-were able to come forth and make an artistic and conceptual contribution to the dish and the event. I was confronted with my ability to move beyond mere preference and to acknowledge my ability to appreciate bitterness, which is an acquired taste, a marker of enculturation (bitterness is a defensive mechanism in plants to discourage being eaten by animals (McGee 2004, 271).

After Dark was a one-off, exploratory event. It was not a product in the strictest sense, reproducing itself for profit. But nevertheless, it furnished its diner-audience with a certain amount of cultural capital and, at $£ 65$ for a ticket, was not a cheap experience (though the politics of cost is more complex, given the need to cover costs and adequately remunerate the performers and workers). Despite this, it was an intoxicating experience, which encouraged different kinds of reflection on the body and the self. The radical potential of intoxication to unnerve, unsettle, make strange and pose questions is not necessarily diminished through its participation in economies of experience, even though there is an attempt to co-opt sensory experience itself as a commodity.

\section{Conclusion}

Serres' model of the two mouths is indicative of two modes of knowledge: that of dissecting analysis and that of sensory experience. Part of the project of The Five Senses was to legitimise the knowledges of sapience; the revelations that can occur through the body and the senses. And in his philosophy of confusion, these two modes of knowledge pour together and are inseparable. Just as Serres offers two mouths, we can think of two kinds of intoxication: the first, anaesthetising, unthinkingly giving oneself over to cultural codes and the status quo, even if it seemingly offers an escape; the second, a process of making strange or defamiliarising. It is in the latter that there is potential for resistance to the commodification of live(d) experience: it can reveal how we are caught between the two orders of knowledge; it can allow us to dwell in their confluence; and it can make space for reflections on the body and its cultural framing and construction. In that awareness of estranged intoxication, this kind of knowing has the potential to resist overdetermination by the logic of commodification and to find a different experience of the senses that is revelatory and not merely for the sake of 'having experienced'.

\section{Notes}

\footnotetext{
1 https://kayewinwood.com/project/after-dark/

2 In David Howes' encyclopaedic entry on the senses, he writes that 'The traditional Western sensory model holds that the senses are five in number, and that each sense has its proper sphere. [...] The senses are also informally ranked, with sight being considered the "highest" most informative, objective, rational, aesthetic and "civilized" of the senses. [...] Both sight and hearing are conventionally set off from the "lower", subjective, emotional, unaesthetic, and animalistic or "brute" senses of smell and taste and touch' $(2015,615)$.
} 


\section{Works Cited}

Baudrillard, Jean. 2014. Screened Out. Translated by Chris Turner. London and New York: Verso.

Howes, David. 2015. "Senses, Anthropology of the." International Encyclopedia of the Social \& Behavioral Sciences 21: 615-20. https://doi.org/10.1016/B978-0-08-097086-8.12224-X

Jameson, Fredric. 1999. Brecht and Method. London and New York: Verso.

McGee, Harold. 2004. McGee on Food and Cooking: An Encyclopedia of Kitchen Science, History and Culture. London: Hodder \& Stoughton.

Serres, Michel. (1985) 2016. The Five Senses: A Philosophy of Mingled Bodies. Translated by Margaret Sankey and Peter Cowley. London: Bloomsbury.

\section{Biography}

Paul Geary is a Lecturer in Drama at the University of East Anglia. He completed his PhD at the University of Bristol, following which he was a Teaching Fellow at the University of Birmingham and a Visiting Lecturer at the University of Birmingham, De Montfort University and the University of Wolverhampton. His research focuses on the senses, food, performance and philosophy, in particular engaging with the work of Martin Heidegger, Michel Serres, and Slavoj Žižek. He is engaged in creative consultancy for a restaurant and is on the project team for an AHRC research network entitled Incubate-Propagate: Towards Alternative Models for Artist Development in Theatre and Performance.

(c) 2020 Paul Geary

cc) (†) Except where otherwise noted, this work is licensed under a Creative Commons Attribution(c) NonCommercial-ShareAlike 4.0 International License. 